\title{
A PRESENT VALUE APPROACH TO ANALYSING RESIDENTIAL PROPERTY
}

\author{
PETER RICKWOOD and ANGELO KARANTONIS \\ University of Technology, Sydney
}

\section{ABSTRACT}

We adopt a simple Present Value (PV) methodology to investigate the interaction between interest rates, inflation and taxation on the fundamental value of residential real estate for a rational investor with varying degrees of risk-aversion. This approach allows the calculation of the fair present value of residential real estate from only a small number of macro-economic variables, and avoids the need to use historical data to calibrate a model. A PV approach can explain some of the more perplexing results obtained in prior work on residential real estate, such as the inability to consistently find a strong negative correlation between property prices and interest rates. Actual property prices are broadly supported by underlying fundamental value (as determined by our PV model) prior to the mid 90s. Our model suggests that the global policy shift to independent central banks with inflation-targeting mandates has important implications for property values.

Keywords: Present value methodology, residential property, real interest rates, inflation

\section{INTRODUCTION}

Analysis of real estate is now, and has been for some time, quite sophisticated. Commercial real estate particularly has been subjected to rigorous financial analysis using various capital asset pricing models (Scott, 1990; Liu, 1994; Hughes, 1995). There is a wealth of analysis on the effect of macro and micro-economic factors on commercial real estate, as well as much work on commercial real estate and the role of real estate trusts in the construction of optimal investment portfolios (Gyourko and Nelling, 1996; Chun et al., 2004).

Residential real estate has also been well covered, but there has been less analysis, stemming from the financial asset pricing tradition used in commercial property and equities, with papers like Spellman (1981), Meese and Wallace (1994), Poterba (1984), and Hwang et al. (2006) being notable exceptions. Instead, the most common approach has been to estimate demand via regression, with economic or other measures as explanatory variables. Such an approach has been useful, especially for spatial analysis, with papers on the effect of proximity to rail (Bowes and Ihlanfeldt, 2001; Gibbons and 
Machin, 2005), schools (Bogart and Cromwell, 2000; Reback, 2005), churches (Carroll et al., 1996), and pollution (Anselin and Le Gallo, 2006). Auto-regression has also been used to analyze the effect of macro variables such as unemployment, interest rates, and the like, on house prices (Harris, 1989; Reichert, 1990).

Despite the extensive analysis that has been performed, puzzles remain. Consider, for example, the effect of interest rates and inflation ${ }^{1}$ on residential house prices. Almost universally, it is assumed that interest rates are negatively related to house prices, and inflation positively related, and most studies back this up (Gyourko and Linneman, 1988; Harris, 1989; Anari and Kolari, 2002), but the evidence is not strong. In their analysis of the home-owner market, Painter and Redfearn (2002) state: "To date, there is little evidence of a significant, independent, role for interest rates despite their clear marginal effects". It is not uncommon for studies to find significant, but weak relationships for interest rates (Harris, 1989; Goetzmann and Ibbotson, 1990), and inflation (Gyourko and Linneman, 1988). For more thoroughly studied commercial real estate, many studies have found inflation to be negatively associated with returns (see Chun et al. (2002) for a summary). Knowing the directional effect of inflation (+ve) and interest rates (-ve) is important, but our understanding of the magnitude of these effects, or the interaction between them (for they are surely not independent), is limited. Furthermore, the effect of inflation is inconsistently modelled, reflecting uncertainty of the causal pathways through which it influences property prices. Some studies 'eliminate' inflation by using real interest rates and deflating house prices back to some constant dollar (Reichert, 1990; Abelson, 1997), while others include inflation and interest rates as separate factors in a regression (Goetzmann and Ibbotson, 1990), despite the fact that they are clearly highly temporally correlated. In many regressions, the effect of country-specific taxation regimes is either ignored (as in Reichert (1990); Abelson (1985)), or included in some ad hoc manner, such as using dummy variables to compare countries with and without mortgage deductibility, although studies where authors have taken an asset-pricing approach have tended to be more systematic in their modelling of the effect of taxation (Summers, 1981; Poterba, 1984). Notwithstanding the complicated nature of the modern housing market, the inability to specify clear relationships between even 'obviously' significant macro variables is a problem. Despite the importance of residential property (it is still the most valuable asset most people ever acquire), the equivocal nature of research endings makes it difficult for even large, well resourced bodies to make sense of residential property markets. When such bodies do issue reports on residential property, they thus tend to be primarily descriptive in nature rather than analytical (IMF, 2004; OECD, 2005).

At worst, the (auto)regression analysis of real estate on historical data can simply be an ex post explanation of observed data. In such cases, regression will fail to capture actual

\footnotetext{
${ }^{1}$ Since countries measure inflation differently, we should make clear that, by inflation, we mean consumer price inflation only, not any measure of asset inflation.
} 
market dynamics, and will be neither useful in understanding the causes of past market behaviour nor reliable in anticipating future market responses. The problem is that the alternative approach (asset pricing) is more difficult in a residential context, as data is much less readily available than in other asset markets such as equities. This perhaps explains the limited number of papers looking at asset pricing approaches to residential real estate. Certainly the more sophisticated approaches are not generally feasible, but we believe that taking a simple asset pricing approach still yields insights into important dynamics of the investor residential housing market.

The aim of this paper is to use PV analysis $^{2}$ to develop a specific closed-form mathematical equation to model the way in which interest rates, inflation, and taxation interact to affect property prices. While the PV approach is not a good predictor of asset values $^{3}$, we show that taking such an approach produces valuable insights into the role that interest rates, taxation and inflation should play in determining residential property prices. For concreteness, we illustrate the application of such an approach to data for Australian real estate, dating back to 1982, before discussing some more general implications. The approach is an extension of work that examines the relationship between house prices and rents, like Spellman (1981). More recent work with some similarity is that done on the San Francisco residential market (Meese and Wallace, 1994), and the Korean condo market (Hwang et al., 2006), respectively, but our analysis is simpler and conclusions more general in nature.

Our PV model suggests that it is the non-linear interaction of taxation, long-run inflation and interest rates that affects property values, and treating these variables as independent, or even linearly dependent, is a dangerous practice.

\section{METHODS}

We adopt a simple PV model. Specifically, we use discounted cash-flows (i.e. rents) to estimate the present value of residential property. We thus begin with the standard finance text-book definition of an asset's present value, as calculated from discounted future cashflows:

$$
V=\sum_{t=1}^{\infty} \frac{r(1+G)^{t}}{(1+D)^{t}}
$$

where $\mathrm{r}$ is the gross rental return of the asset, $\mathrm{G}$ is the future nominal growth rate in rent, and $\mathrm{D}$ is the discount rate required by the investor as compensation for risk, lack of liquidity, or any other factor.

\footnotetext{
${ }^{2}$ Also referred to as Discounted Cash Flow or Dividend Pricing.

${ }^{3}$ For this, a method that is calibrated on historical data, such as auto-regression, is more useful.
} 
We re-express equation 1 slightly by expressing income growth in real terms (i.e. by separating out inflation I and real income growth g), as this aids in our analysis later on. We also normalize the equation so that instead of calculating total value $\mathrm{V}$, we instead calculate $\mathrm{V}_{1}$, the value of $\$ 1$ invested in property. Doing this, we get equation 2:

$$
V_{1}=\sum_{t=1}^{\infty} \frac{y(1+I+g)^{t}}{(1+D)^{t}}
$$

where $y$ is the percentage rental yield of a property.

Using discounted cash flow to value an asset is difficult in practice. The value obtained hinges critically on the growth (g) and discount (D) rates applied. In addition, sums over an infinite time horizon often pose a problem, and in practice, the sum is usually limited to some non-infinite time horizon or is split into two parts. Certain niceities in our data will allow us to overcome the difficulty of specifying $g$ and will render the calculation of the sum over an infinite time horizon via equation 2 possible, leaving only the specification of $\mathrm{D}$ a problem. Also, the use of equation 2 has constant discount and growth rates. Although growth and discount rates will vary over time, the distortions introduced in an infinite sum by using the long term average are minimal unless $\mathrm{g}$ or $\mathrm{D}$ are exceedingly volatile, which is not supported by historical data (see section 3). We choose not to complicate the analysis by extending the simple PV model, as is commonly done in equity and commercial property valuations, because the simple model is sufficient for our purposes, which are primarily illustrative.

We make these initial assumptions, which we will relax later:

Assumption 1 (Rental market efficiency): Rental return is the efficient market equilibrium value for the rent value of a property.

Assumption 2 (Perfect liquidity): Investors require no discount for lack of liquidity. Or, equivalently, the real-estate market is perfectly liquid.

Assumption 3 (No landlord costs): Net rental return equals gross rental return. That is, there are no maintenance costs, council taxes or levies, and no property management fees. Assumption 4 (No transaction fees): There are no transaction costs associated with either buying or selling property.

Since assumption 1 is clearly quite crucial to our whole analysis under a PV framework, we justify it by pointing out that the rental market is more liquid than the sales market, and that irrationality seems to be less likely in the rental market than the sales market. As already noted, the choice of $\mathrm{D}$ is always contentious, so we simply avoid dealing with it, at least initially, by making the following assumption of our hypothetical real-estate investors, which we will relax later: 
Assumption 5 (Risk Neutrality): Investors are indifferent to risk - that is, they require no compensation (discount) for investing is an asset with higher risk. Equivalently, they see holding property and cash as risk-free.

Since we assume no discount for risk, we need only apply a discount for the opportunity cost of investing in cash, as opposed to real estate (i.e. $\mathrm{D}=(\mathrm{I}+\mathrm{i})$ ). Equation 2 thus simplifies to:

$$
V_{1}=\sum_{t=1}^{\infty} \frac{y(1+I+g)^{t}}{(1+I+i)^{t}}
$$

where $i$ is the real cash interest rate.

For equation 3 to converge, we require $g<\mathrm{i}$. However, we present evidence in section 3 that, at least for our Australian data, $\mathrm{g} \leq 0$, so we are in no danger on this front, since $\mathrm{i}$ is certainly positive. Since our sum is thus clearly finite, we avoid both the need to split equation 2 into two parts, and the need to use a non-infinite time horizon. Equation 3 converges to:

$$
V_{1}=\frac{y(1+I)}{i}
$$

Now, when $V_{1}=1$, the cash flow of $\$ 1$ invested in property is equal to the cash flow of $\$ 1$ invested in cash. Thus, for a risk-neutral investor to consider investing in property, we must have:

$$
\frac{y(1+I)}{i} \geq 1
$$

Note that all of our simplifying assumptions, bar assumption 1, thus far have the effect of increasing the attractiveness of property as an investment. Relaxing any of the assumptions will decrease the cash flow, and hence the estimate of present value. As a result, we can be confident that our PV methodology will give a firm upper bound on the fair value of property.

An important feature of our analysis is that it eliminates the need to model investor expectations of capital gain, which is an often quoted reason for investing in property. In a PV methodology, appreciation in the capital value of property is purely a reflection of the future income generating capacity of the property. While we do not include investor leverage explicitly in our analysis, the principal appeal to investors (transfer of income into capital, for tax purposes) is covered by our model. Explicit consideration of a leveraged investor would require some adjustments to account for different 
borrowing/saving cash rates, but this is beyond the scope of this paper, which simply demonstrates the application of a PV model.

\section{APPLYING AND EXTENDING THE MODEL}

For Australia, we use Real Estate Institute of Australia (REIA) data (REIA, 2006) for median 3 bedroom house rents and median 3 bedroom house prices in each of the major mainland capitals. From this data, we construct national housing and rental indices, based on Australian Treasury weightings reported in Abelson et al. (2005). While using national aggregate figures masks significant variations in regional sub-markets, the aggregate trends are still instructive, particularly of the eastern states, which obviously dominate the weightings.

In deriving equation 4, we assumed (without evidence) that the long term rate of growth in rent $g$ was zero. REIA figures show that the median rent on a 3 bedroom house has failed to keep up with inflation. That is, there has been a real decline in median rents. Using median rent is imperfect, since it does not necessarily correspond to actual fluctuations in rental income, due to sampling effects. Ideally, one would like to know how the rental income on individual properties is changing over time. The Australian Bureau of Statistics (ABS) collects just such information for all major cities and publishes a rent index (ABS, 2006). Figure 1 shows that the rental price index compiled by the ABS has grown at a slightly slower rate than the overall consumer price index compiled by the same authority. This rental index is compiled at some expense: it involves repeat sampling throughout all the capital cities, and is not distorted by sampling or compositional change, as these are both controlled for (see ABS (2005) for detailed description of the methodology). We can thus be confident that it is an accurate calculation of actual movements in rents. 
Figure 1: Rental process and inflation: 1972-2005

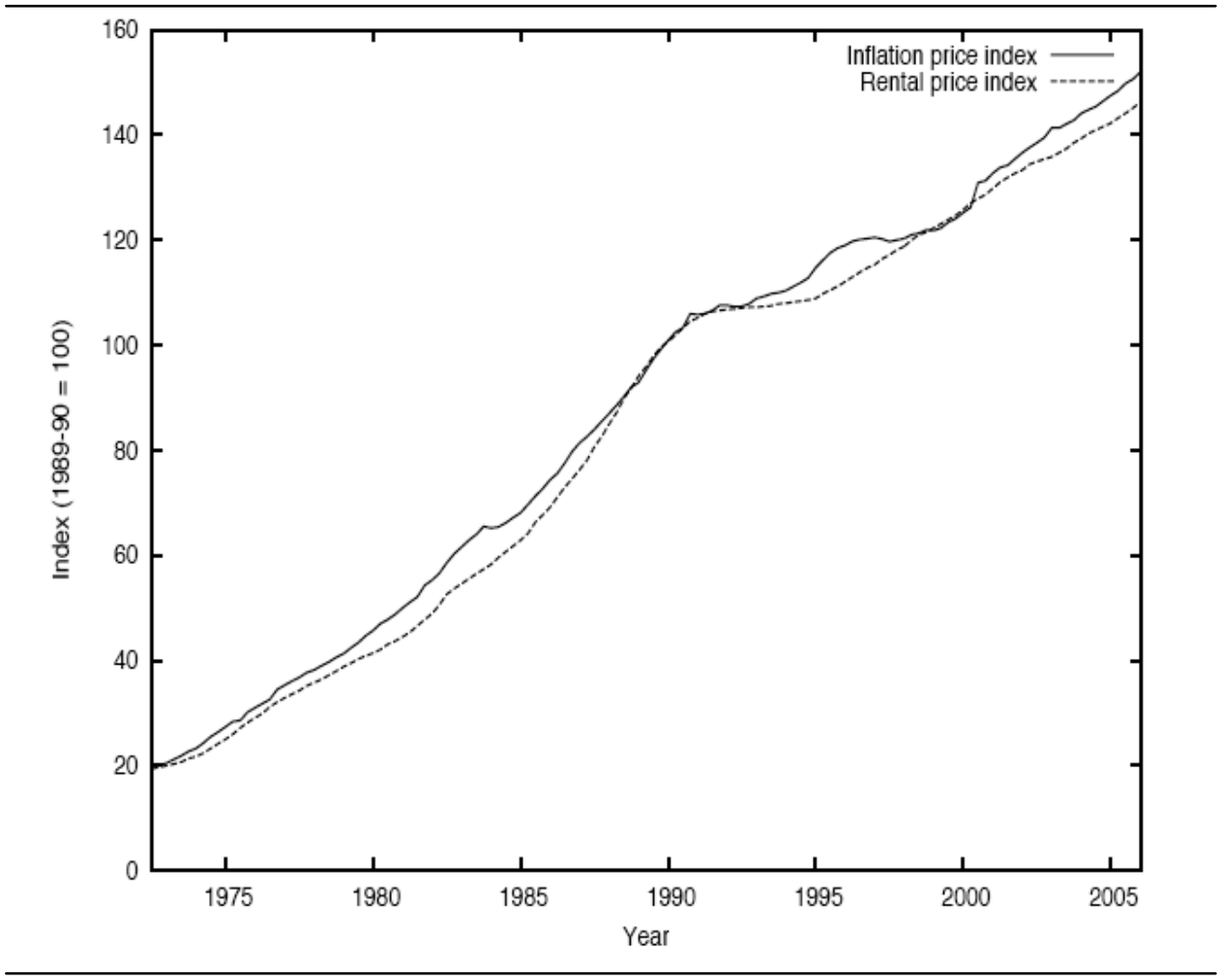

While our price data is only for median 3 bedroom houses, whereas the ABS data is for all housing (detached and otherwise), the fact that both the ABS and REIA data both show rental growth to be less than inflation over a long time period makes it seem reasonable to assume that the real rental growth rate $\mathrm{g}$ is zero.

Because our analysis is performed over an infinite time horizon, we cannot use comparatively short term financial instruments, such as 10 year bonds, to estimate long term inflationary expectations. However, the Reserve Bank of Australia (RBA) has independent control of monetary policy to keep inflation within the 2-3\% range, so we choose a value of $3.5 \%$ - above the top end of this range ${ }^{4}$. Although inflation was much higher than this in the 1980s, this was in the absence of an independent inflation targeting central bank. For the long run estimate of $i$, we use the Australian Treasury issued capital protected bonds (whose capital value is indexed to inflation), as a guide,

\footnotetext{
${ }^{4}$ Lower estimates for I would result in a weaker bound.
} 


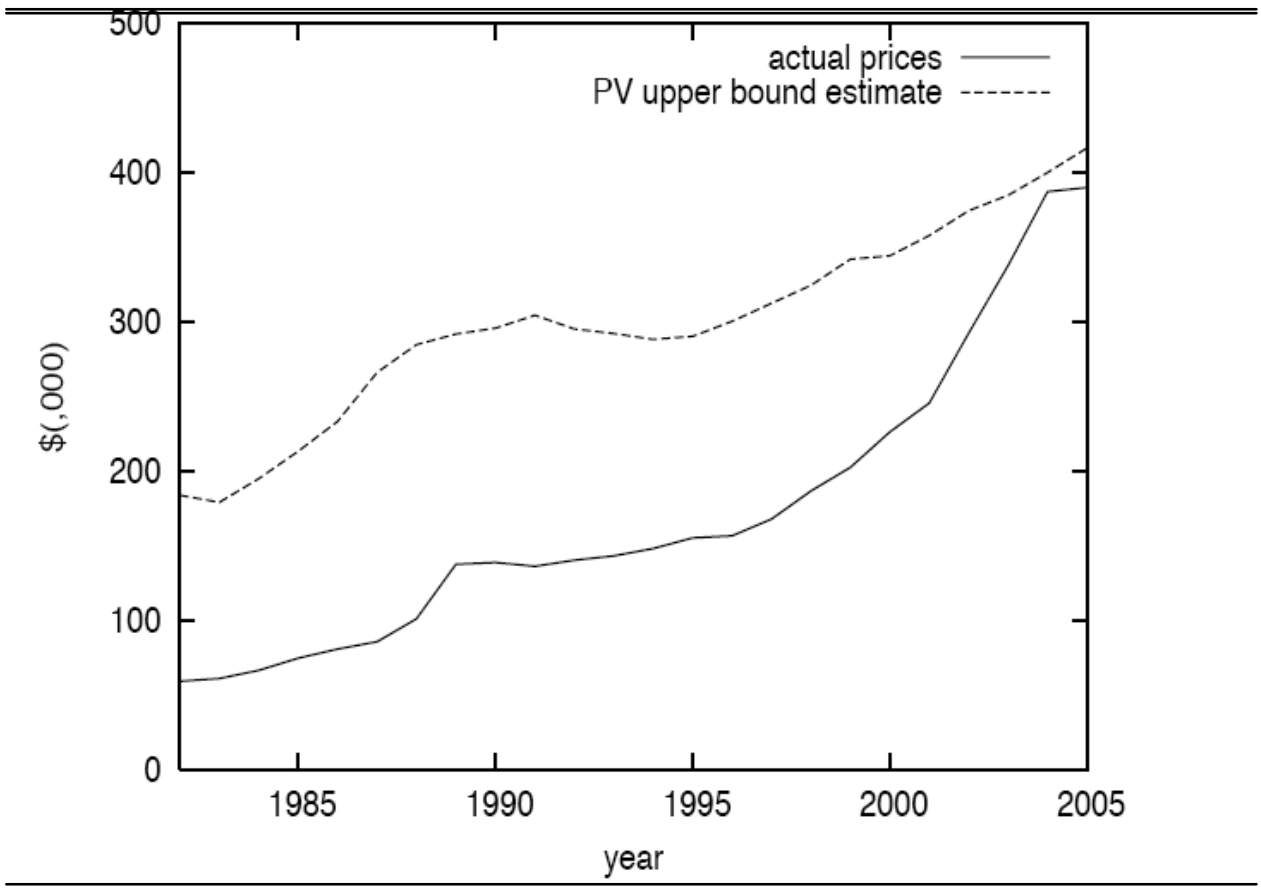

which indicate that a long term real cash rate of $3.5-4 \%$ is probably a reasonable estimate, so we take the bottom of this range and reduce it by $0.5 \%$, for a conservative estimate of $3 \%$. This is also conservative compared with other general international estimates of long term real cash rates in free markets. We are now in a position to solve inequality 5. For each year, we calculate the discounted cash-flow value of property, with future inflation I of $3.5 \%$ and real interest $i$ assumed fixed at $3 \%$.

Figure 2 shows actual median prices over our study period compared with the maximum values required for inequality 5 to hold. Figure 2 shows, comfortingly, that our upper bound always holds, although the most recent boom in property prices comes close to breaching it. We now extend our analysis by relaxing some of our assumptions, since they result in a very strong upper bound - almost certainly higher than is warranted.

\section{Extending the model}

The assumptions made to simplify the analysis thus far have the effect of inflating the estimate of the fundamental value of real estate. Firstly, we relax some of the assumptions and, secondly, introduce consideration of taxation to obtain a more realistic assessment of the value of Australian real estate to a property investor. Leaving taxation aside for the moment, as it warrants some further explanation, we must include some new variables to 
account for complexities that have been thus far ignored. These variables are: $n$, the net rent as a proportion of gross rent; $d$, the property related discount rate (thus far assumed to be 0 ); and p, property purchase costs as a proportion of a property's purchase price. Including these, and assuming convergence, so that we may simplify the infinite sum, we get equation 6 :

$$
\begin{aligned}
V 1 & =\sum_{t=1}^{\infty} \frac{n y(1-p)(1+I+g)^{t}}{(1+I+i+d)^{t}} \\
& =n y(1-p) \frac{1+I+g}{i+d-g}
\end{aligned}
$$

\section{Introducing tax considerations}

Up to this point in the analysis, we have ignored the effect of taxation on real estate. Implicitly, since a discounted cash-flow sets up an equivalence between capital and income (capital is just discounted future income), the fact that capital and income are typically taxed differently will distort the analysis. We now correct for this.

Most countries tax income as it is accumulated at the appropriate marginal tax rate, whereas increases in capital value are taxed only on realization, if at all. In the limit, one can thus defer (and hence avoid) capital taxes altogether. For an investor on a marginal income tax rate $\mathrm{T}$, altering equation 6 to account for tax results in equation 7 :

$$
\begin{aligned}
V 1 & =n y(1-p) \sum_{t=1}^{\infty} \frac{(1-T)(1+I+g)^{t}}{(1+(1-T)(I+i)+d)^{t}} \\
& =n y(1-p)(1-T) \times \frac{1+I+g}{i(1-T)+d-g-T I}
\end{aligned}
$$

Since income is taxed and capital gain is not, we need to multiply all income by $(1-\mathrm{T})$. This means the numerator in equation 7 (representing rental income), but also the two terms in the denominator (I and i), which represent a compounding cash deposit ${ }^{5}$. Since all cash generated from a cash deposit is taxed (including the inflationary component) as it is earned, the nominal compound rate after tax on a cash deposit is $1+(1-\mathrm{T})(\mathrm{I}+\mathrm{i})$. For a rental property, however, while the rental income is taxed as it is earned (i.e. the numerator is multiplied by $1-\mathrm{T}$ ), the asset's earnings (and hence, value) compound independently of taxation.

\footnotetext{
${ }^{5}$ Note that we assume a discount rate independent of tax.
} 
We can see from equation 7 that property is an excellent hedge against future inflation when the investor's marginal tax rate is high. To see this, we only have to note that as I+ $\mathrm{g}-\mathrm{d}$ approaches $(1-\mathrm{T})(\mathrm{I}+\mathrm{i})$, the sum becomes large, and in fact becomes infinite beyond this ${ }^{6}$. It is conventional financial wisdom that property is a tax-shelter for those on high tax rates and is an effective hedge against inflation. From an asset pricing basis, this wisdom is sound (Summers, 1981), and our PV model confirms this. Note that equation 7 is not peculiar to property - it applies to any income generating asset under a tax regime that taxes income and capital differently. What makes its application to property interesting is that property is a low risk asset with fairly stable and predictable income growth (see Fgure 1), and hence has played a significant role in the avoidance of income tax by those on high marginal tax rates.

Our PV model gives a closed form mathematical description of the relationship between taxation, interest rates and inflation. In order to illustrate the application of equation 7, we solve it for our particular case - Australia's real estate market.

\section{EXAMPLE}

We now set up what we consider to be realistic assumptions, and solve for the fair value of property. This will be our rough estimate of the value of property, and no longer any credible upper bound. We will perform a sensitivity analysis on the relevant parameters to show the robustness of the model to our realistic assumptions. Here are the assumptions we make for a realistic analysis:

2\% property related discount rate $(\mathbf{d}=\mathbf{0 . 0 2})$ : Real estate is considered a low risk asset, but is not risk-less, so an investor requires an additional discount of $2 \%$ above the cash rate to compensate for lack of liquidity and increased risk.

$\mathbf{3 . 5 \%}$ real interest rate $(\mathbf{i}=\mathbf{0 . 0 3 5})$ : The real interest rate is held constant at $3.5 \%$ above inflation, justification for which has already been given.

Rental growth tracks inflation $(\mathrm{g}=\mathbf{0})$ : Justification for which has already been given (see Figure 1).

Rental expenses are $25 \%$ of gross $(\mathbf{n}=\mathbf{0 . 7 5})$ : Expenses (land taxes, council levies, water rates, maintenance, real-estate agents fees, and vacant (un-let) periods) are $25 \%$ of gross rent.

\footnotetext{
${ }^{6}$ The problem of non-finite sums is inherent to PV analysis, and while it is clear than it makes no sense for an asset to have infinite value, it is a limitation of our simple application of PV that our results break down beyond a certain point.
} 
5\% transaction cost to buy $\mathbf{p}=\mathbf{0 . 0 5}$ : Transfer/Transaction tax on the purchase of property is universal in Australian states and territories, and on the median house price in 2005 , range from around 3\% of the property's value in Queensland to 5\% in Victoria. Legal fees are an additional cost.

$42 \%$ income tax rate $(\mathbf{T}=\mathbf{0 . 4 2})$ : We use an indicative tax rate of $42 \%$ on income, which is approximately the second-highest marginal tax rate in Australia ${ }^{7}$ (including a public health insurance levy), and we assume property investors are in this bracket ${ }^{8}$.

The risk-related discount rate applied here $(2 \%)$ is low, taking into account the widespread perception of real-estate as a low risk asset, but we offer no concrete justification for choosing it. We do not believe it useful, or possible, given available data, to engage in an in-depth analysis of the proper discount rate that should apply, and so we settle for a small discount rate, and merely note that our PV estimate will probably be too high. We take a similar approach to the estimation of other parameters; in general, choosing to err on the side of values that will overstate the present value of real estate.

Putting all our assumptions together, equation 7 simplifies to:

$$
\begin{aligned}
V_{1} & =0.75 y \times 0.95 \times 0.58 \times \frac{1+I}{0.035 \times 0.58+0.02-0.42 I} \\
& =0.41325 y \times \frac{1+I}{0.04-0.42 I}
\end{aligned}
$$

Figure 3 shows our PV estimate against actual prices. The trend is instructive, and hints at important structural changes that occurred in the Australian economy in the early-mid 90s. Note that for our best guess of future inflation $(3.0 \%)$, the time period modelled can be split roughly into two sections - the first (pre $\approx 1995$ ) characterized (roughly) by under or fairly valued property, and post 1995 by over-valued property. We contend that prior to 1995, residential property prices were supported by market fundamentals, but that after 1995, they disconnected from these fundamentals. We discuss this in detail in the next section, for the 'shift' coincides with important monetary policy changes in Australia in the early-mid 90 s.

\footnotetext{
${ }^{7}$ The tax scales have changed over our period, so a single 'correct' value does not exist. Currently, the second highest marginal tax rate is $41.5 \%$.

${ }^{8}$ Later analysis (see section 3.3), shows the effect of other marginal tax rates.
} 
Figure 3: A PV estimate of the fundamental value of property against actual prices for varying values of $I$, with a discount rate of $2 \%$

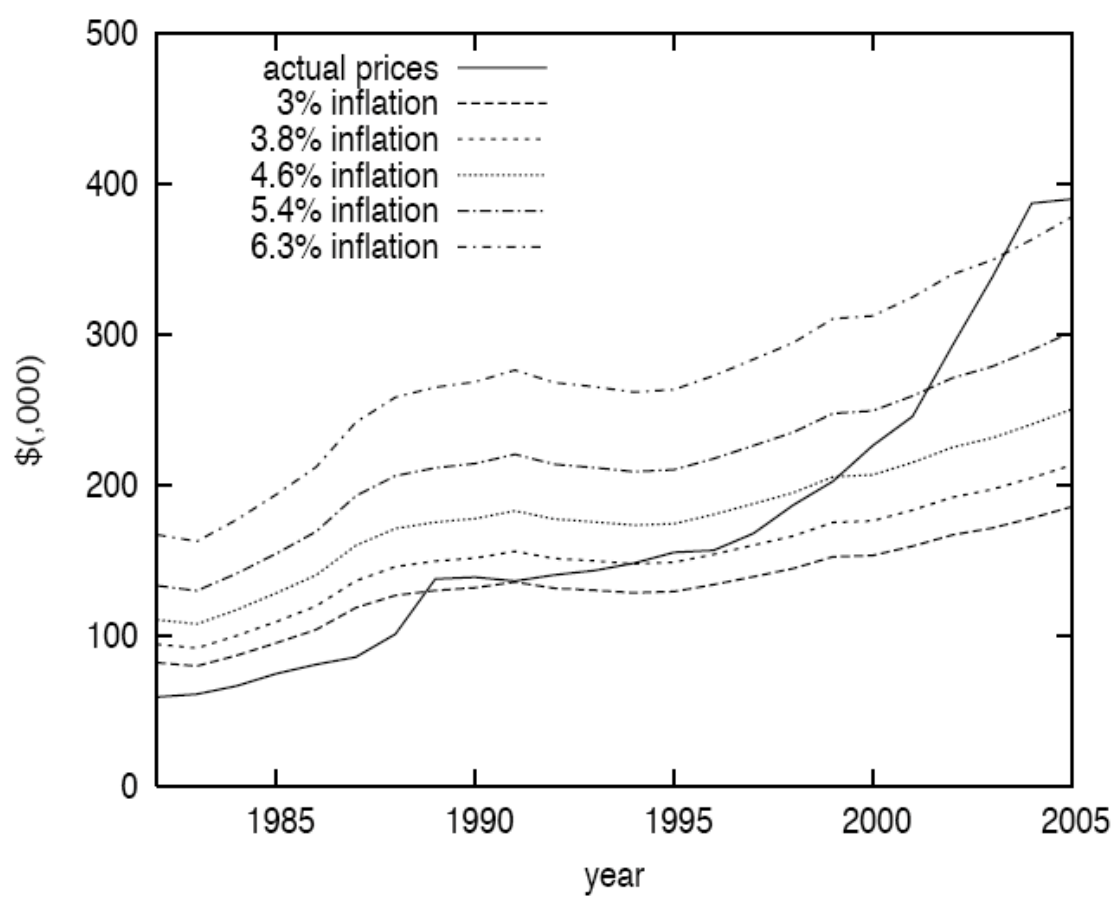

Figure 3 suggests that, unless rational investors anticipate inflation to be at or above its long term geometric mean $(\approx 6.3 \%$ since 1970$)$, current prices are not justified by a PV model. Such an expectation seems hard to justify, given current long term bond yields, and given that while inflation averaged over 6\% in the 25 years to 1993, since 1993 the RBA has an inflation target of 2-3\%. One would thus expect real estate to have suffered a real decline in value some time in the '90s. As an illustration, Figure 4 shows the PV estimate for an investor with inflationary expectations of $6.3 \%$ prior to 1995 and inflationary expectations of 3\% after that period. Instead of the anticipated decline in prices, the period since RBA independence has seen an especially strong surge in property prices. Even assuming an extremely low (1\%) discount rate, Figure 5 shows that real estate in Australia is still overpriced unless one anticipates that the RBA will be unable to keep average inflation within the top of its target range. 
Figure 4: Impact of change in inflationary expectations from $6.3 \%$ to $3 \%$

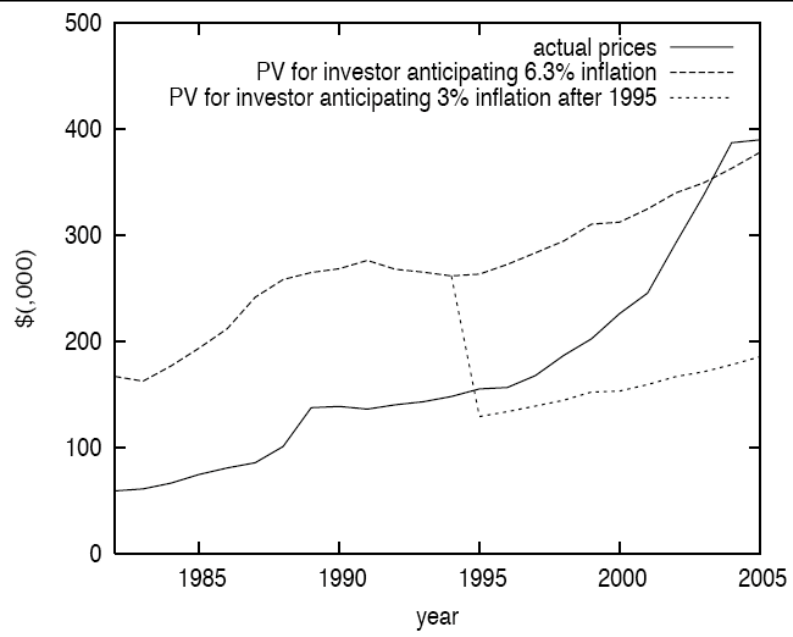

Figure 5: A PV estimate of the fundamental value of property against actual prices for inflationary expectations of $3 \%$ (the top of the RBA's target range), with a discount rate of $1 \%$

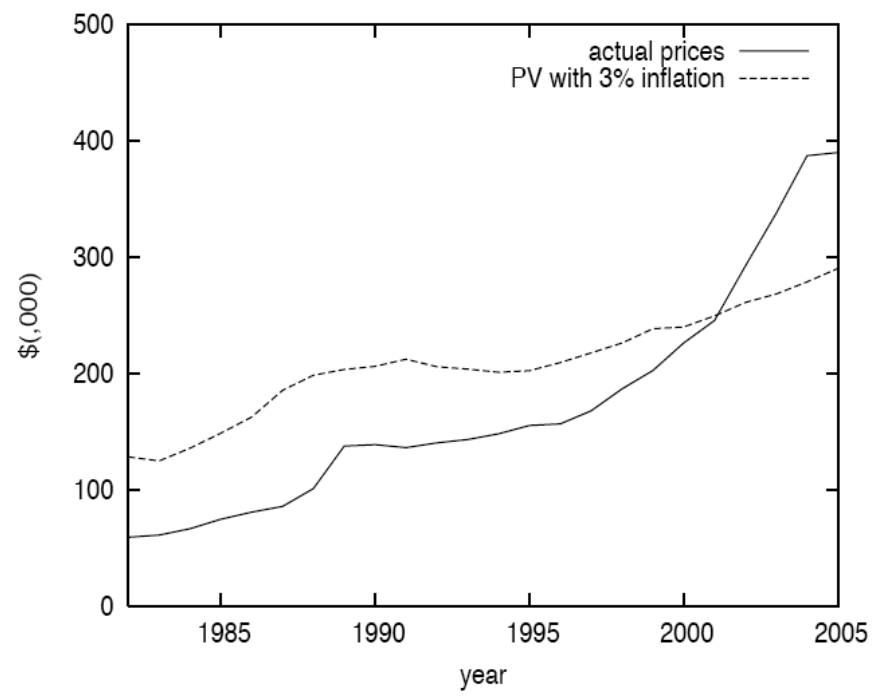


Important simplifications, such as our projections of inflation and interest rates over an infinite time horizon, and our somewhat arbitrary choice of discount rate, place limitations on the general application of equation 7 in determining fundamental prices, although our analysis thus far does strongly suggest that, barring supply-side factors, the recent surge in property investment in Australia is not sustainable, as it runs contra to fundamentals. We suspect the same is true of other Anglosphere economies. Equation 7 is more useful, we believe, in analysing the general effect on property prices of particular changes to taxation (property, capital, and income), interest rates, and inflation. In this spirit, we now perform a sensitivity analysis on the variables in equation 7 .

\section{Sensitivity analysis}

In the following, we first vary a single parameter (holding all others constant), and then selected pairs. The constant values we use are: $\mathrm{g}=0.0 ; \mathrm{d}=0.03 ; \mathrm{I}=0.03 ; \mathrm{i}=0.035 ; \mathrm{T}=$ $0.42 ; \mathrm{y}=1.0 ; \mathrm{n}=0.75 ; \mathrm{p}=0.05$. All of these are realistic values, except $\mathrm{y}$, which is set constant at 1 , which means that the PV estimate produced will be the value of a property for each $\$ 1$ in gross annual rent.

Figure 6: The effect of growth (g) and discount rate (d) on present value

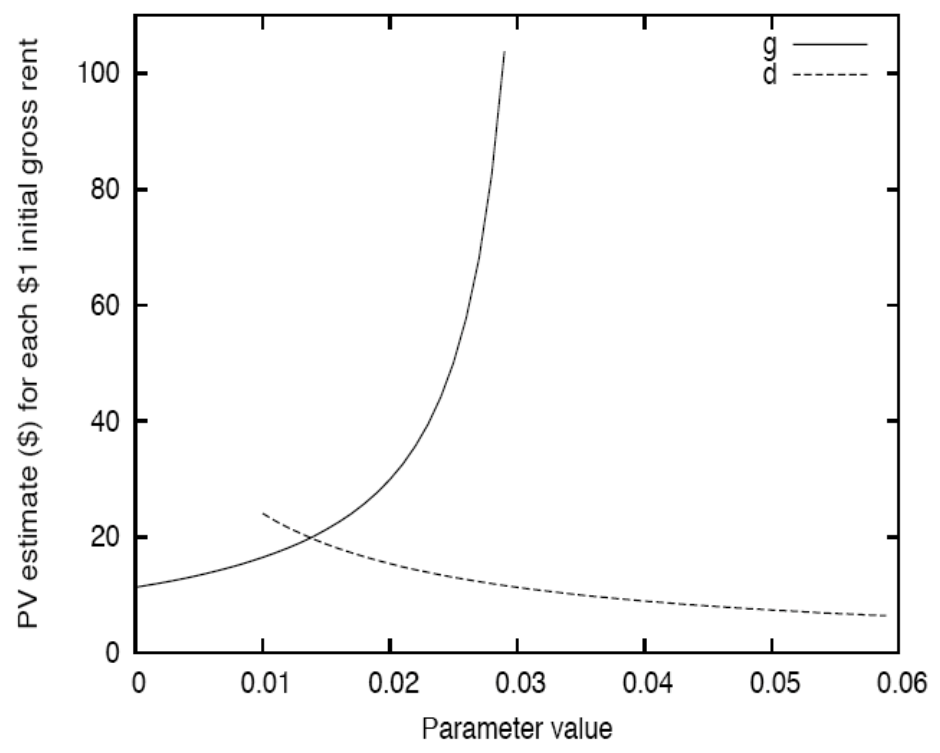

We can see directly from equation 7 that changes in the values of $g$ and $d$ will have a significant effect on the value, and Figure 6 confirms this. Since we argue that $g$ is probably close to 0 , and the choice of $\mathrm{d}$ is problematic, we shall not focus on these 
variables, instead investigating the more interesting relationships between the other variables.

Figures 7 and 8 show the effect of changes to each of $\mathrm{I}, \mathrm{i}$ and $\mathrm{T}$ on the PV estimate from equation 7 , holding all other variables constant ${ }^{9}$. The most interesting figure here is Figure 8 , which shows no sensitivity to the tax rate. This is, however, a little misleading. It seems evident from equation 7 that the marginal tax rate of the investor should have an effect on the value of property to that investor. What Figure 8 demonstrates is that, for the constant parameter values chosen for $\mathrm{i}$ and $\mathrm{I}$, there is a plateau in T (i.e. it has no effect). Other values for $i$ and I change this, as is made clear in Figures 9 and 10. Further, noting that the denominator in equation 7 can be written as $\mathrm{i}-\mathrm{T}(\mathrm{i}+\mathrm{I})+\mathrm{d}-\mathrm{g}$, we see that when $\mathrm{T} \approx$ $\mathrm{i} /(\mathrm{i}+\mathrm{I})$, the taxation rate vanishes from the infinite sum part of the equation, and plays little role in determining the PV. This suggests that empirical studies looking into the effect of marginal tax rates on property investor behaviour (and potentially owneroccupier behaviour) may, for example, find no effect in some property markets where inflationary expectations are low and a strong effect in others with higher inflationary expectations, depending on the tax rate.

Figure 7: The effect of I (inflation) and i (real interest rate) on present value

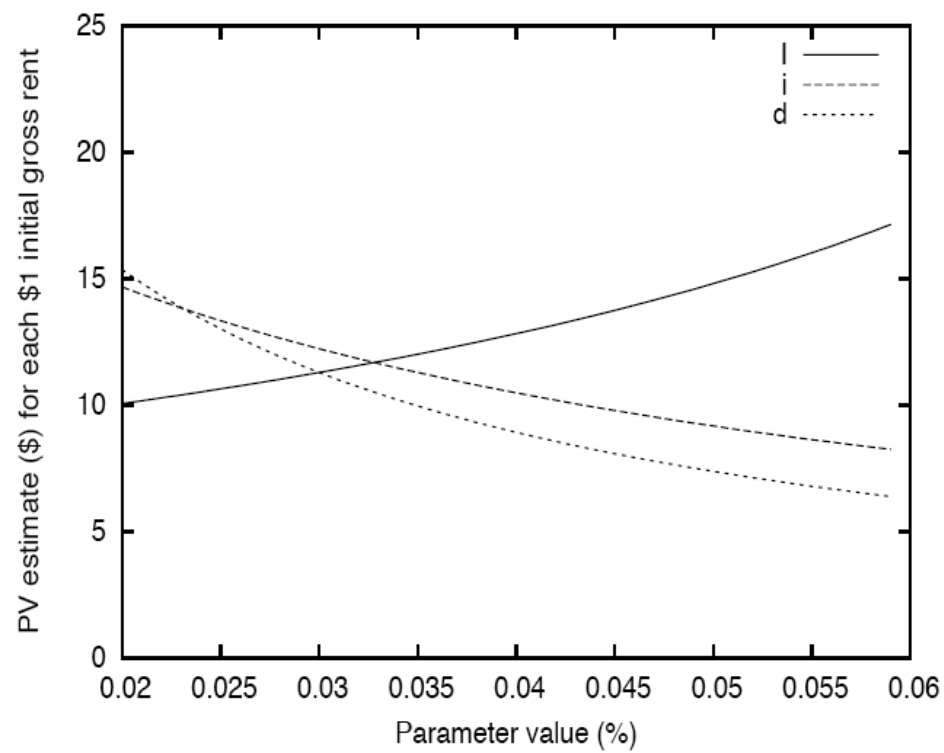

${ }^{9}$ The effect of $\mathrm{n}$ and $\mathrm{p}$ are clear from equation 7 , so we do not show results for these parameters. 

value, with $\mathrm{I}=\mathbf{0 . 0 3}$

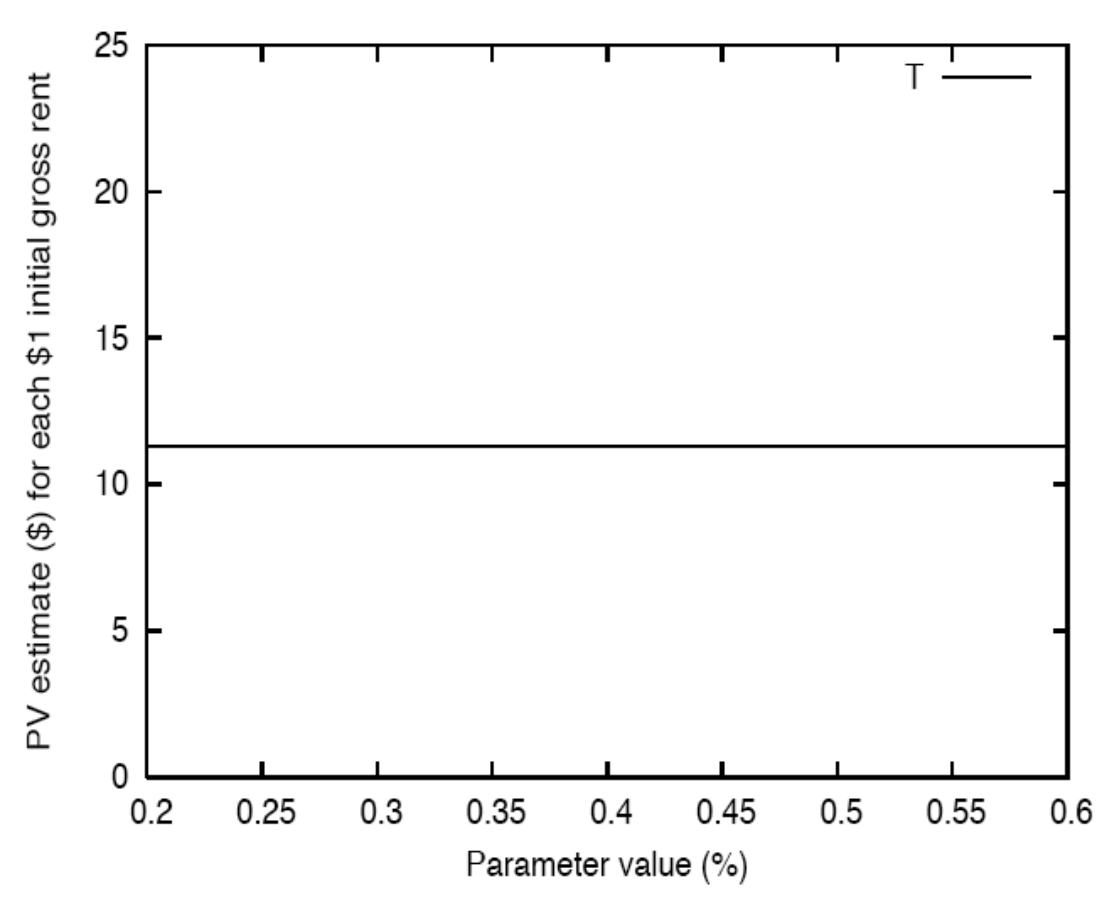

To further illustrate the interaction between variables, we show selected bivariate sensitivity analyses (Figures 9,10 , and 11$)^{10}$. For Figures 9 and 11 , values for non-varying variables are $\mathrm{g}=0.0 ; \mathrm{d}=0.03 ; \mathrm{I}=0.03 ; \mathrm{i}=0.035 ; \mathrm{T}=0.42 ; \mathrm{y}=1.0 ; \mathrm{n}=0.75 ; \mathrm{p}=0.05$. For Fgure $10, \mathrm{I}=0.035$, with all others as for figures 9 and $11^{11}$. Also note that figure 9 has a log-scaled vertical axis, while the others do not.

From our sensitivity analysis, we see that it is $\mathrm{g}, \mathrm{d}$, I, and (in some circumstances) T, that most influence the estimated present value of real estate, and that interactions are important. Even for low discount rates, current actual market values are hard to justify unless inflation (I) averages above 3\%.

\footnotetext{
${ }^{10}$ Again, we do not investigate terms that appear outside the summation in equation 7 , as their influence is clear on inspection, and small anyway.

${ }^{11}$ We alter the value of I slightly for figure 10 because for $\mathrm{I}=0.03$ the PV estimate is insensitive to changes in $\mathrm{T}$, as already discussed.
} 
Figure 9: The effect of varying I and $T$, holding other variables constant

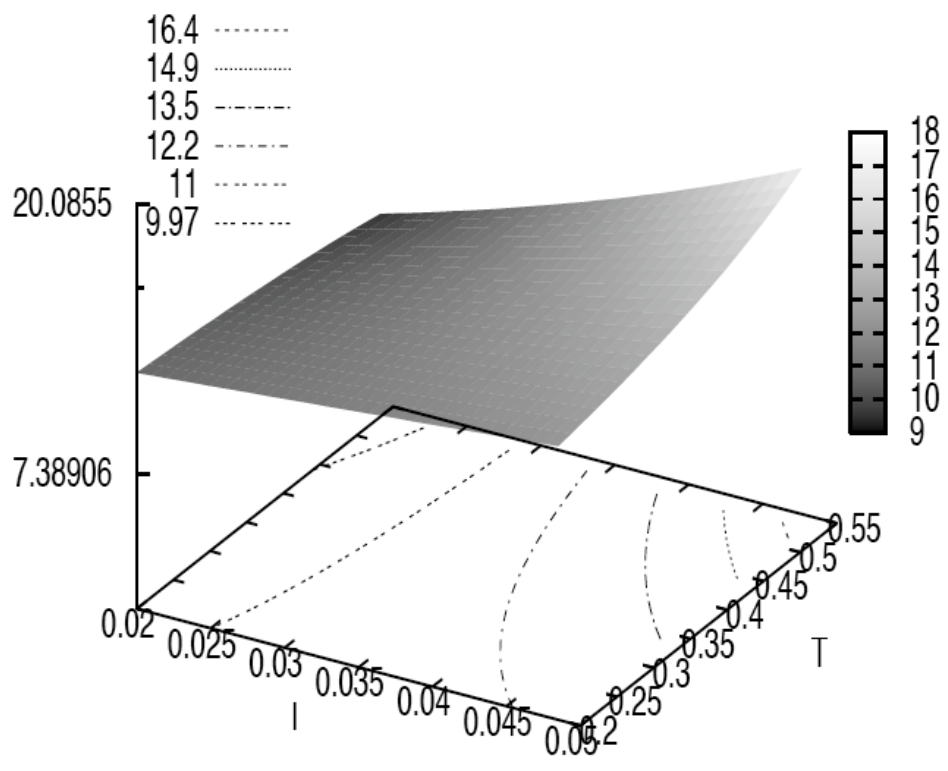


Figure 10: The effect of varying $i$ and $T$, holding other variables constant

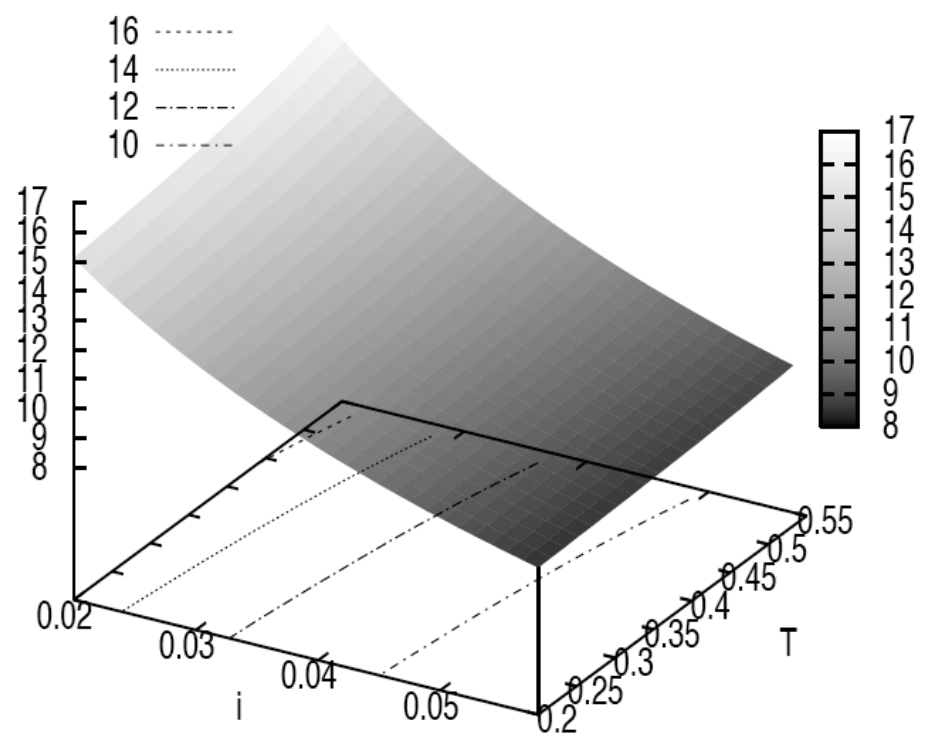




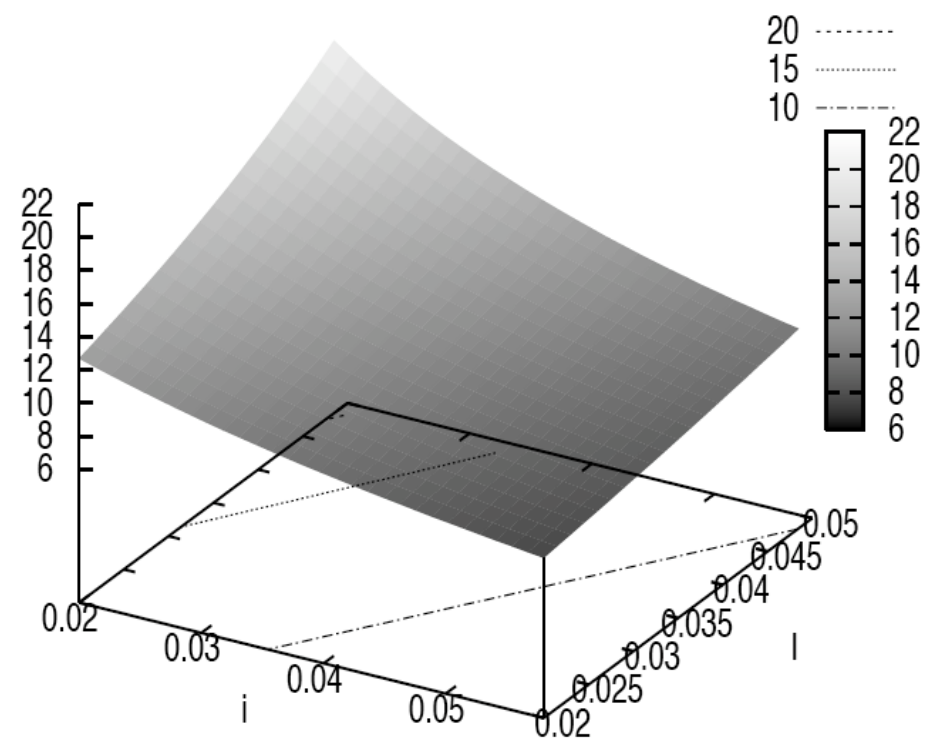

\section{DISCUSSION}

We do not wish to argue that our simple PV model is valuable in estimating the actual behaviour of the residential real-estate market, although we do note (referring back to Figure 3) that a PV methodology can capture some of the dynamics observed in historical data. We also note that Hwang et al. (2006) adopt a PV approach, and use an interesting data-set to show a strong relation between rental income and property value in Korea. Meese and Wallace (1994), in testing the present value for San Francisco, also find that the rental and sale markets are cointegrated in the long run, but experience significant idiosyncratic movement in the short term. We suggest that the current period of price growth in Australia, and probably in other countries, is just such an idiosyncratic movement. Current market 'corrections' in the USA and Australia lend support to this theory, but time will tell.

Although our analysis is restricted to investors only, it seems plausible that potential owner-occupiers behave at least partially like investors. That is, they are not driven solely by personal circumstance (i.e. family structure, income, age, and so on), but also by factors such as taxation and interest rates. In other words, even the family home is being 
seen as an investment. Developing further refined PV models for residential property, or a hybrid PV/hedonic model (to model combined investor and owner-occupier values) may be valuable areas for future research.

The main aim of this paper is not, principally, to estimate the 'fair value' of real estate, although our simple PV model does produce such an estimate (see Figure 4). Instead, we show that PV analysis can provide insights into what the general rational investor response should be to changes in monetary and fiscal policy. It provides a clear explanation for the consistent link between inflation and property appreciation, and illustrates the rationality of investors on high marginal tax rates investing in property even when nominal interest rates are high. It also shows that the interaction between interest rates, inflation and taxation may explain the inability of researchers to find stable relationships between these variables and property prices.

On a policy front, our PV model suggests that, provided supply side issues are not dominant $^{12}$, quelling long term inflationary expectations may be more effective than keeping real interest rates low in maintaining housing affordability (Follain and Ling (1988) come to the same conclusion in a separate analysis). This is an especially important observation given the global trend towards independent central banks with inflation targeting mandates. In Australia, for example, the Reserve Bank of Australia was given (non-legislated) independent control over monetary policy in 1993, and was tasked with maintaining inflation in the 2-3\% range. The RBA's independence to set monetary policy was legislated in 1996. We suggest that 1993 marks the beginning of low inflationary expectations ${ }^{13}$, but property prices have surged since then; something that can only be justified in a PV context by: a deviation from market fundamentals; an extremely low discount rate for property; or by inflationary expectations above the RBA's target ceiling. Prior to 1993, inflationary expectations were high, and, indeed, the government had been willing to live with moderate inflation and moderate nominal rates, as the alternative (low inflation and high real rates), was politically unpalatable. In such an environment, the PV of property is high, but when inflationary expectations fall, the value of property (at least to a rational investor) should also fall. This has not happened (as Fgure 4 shows), and given that much of the boom during the post-1993 period was driven by investors, we believe investors have not yet factored in RBA independence and the corresponding low-inflation environment. An alternative is that housing investors believe the RBA will be either unable or unwilling to use monetary policy aggressively enough to keep inflation low.

If inflation is anticipated by housing investors, but not by bond markets ${ }^{14}$, and if in fact more general measures of inflation subsequently do increase, countries with monetary policy set by politicians will likely be less vigilant in increasing rates quickly, and hence

\footnotetext{
${ }^{12}$ We acknowledge that this often not the case, but we do not wish to address supply side issues in this paper.

${ }^{13}$ We base this claim on bond market behaviour.

${ }^{14}$ Current bond rates do not indicate long term inflationary expectations.
} 
we would expect higher housing prices in these countries (relative to rents). Countries like Australia, Canada, the UK, and, to a slightly lesser extent, the US ${ }^{15}$, with independent central banks, are likely to suffer larger declines in house prices due to the possibility of lower inflation and high real interest rates during monetary tightening phases. More research into the housing markets of countries with different inflationary expectations, taxation and central bank independence would be valuable.

Our methodology and general reasoning applies in general to all capital assets, but we believe that property is a particularly important area to focus on, due to the fact that it is a low risk asset with income that is typically stable, and tracks inflation ${ }^{16}$, and, as a result, has been used extensively as a safe harbour for the capital of those on high marginal tax rates.

In this paper, we have demonstrated that, under certain assumptions, one can express the inter-relationship between property value (as calculated from discounted cash-flows), interest rates, inflation and taxation, and that such an approach is useful in exploring the potential effects of long term changes to monetary and fiscal environments; something we know should have an effect on asset prices, and which has been confirmed for REITs (Chun et al., 2002), but not for residential housing. In the case of the Australian market, our model suggests that property values should decline in a (post 1993) low-inflation environment. The fact that the market has surged during this period gives us reason to think that property investors have not adjusted to the new monetary policy environment, or else do not believe that the RBA will be able to contain inflation in the $2-3 \%$ band in the long term. We foresee the potential for political pressure if central banks raise rates aggressively to contain inflation, something which they have not yet had to do. To us, the ultimate determinant of whether current housing prices are sustainable will be whether independent central banks exert (and retain) their independence.

\section{REFERENCES}

Abelson, P. (1985). House and land prices in Sydney from 1925 to 1970. Urban Studies, 22:521-534.

Abelson, P. (1997). House and land prices in Sydney from 1931 to 1989. Urban Studies, 34(9):1381-1400.

Abelson, P., Joyeux, R., Milunovich, G., and Chung, D. (2005). House Prices in Australia: 1970 to 2003 Facts and Explanations. Department of Economics, Macquarie University, Australia, http://www.econ.mq.edu.au/research/.

\footnotetext{
${ }^{15}$ The U.S. central bank considers a number of factors when deciding on monetary policy, rather than being purely inflation targeting, although the difference is generally small in practice.

${ }^{16}$ Indeed, rent is a significant component of many nations' inflation indices.
} 
ABS (2005). Catalogue number 6461.0. Australian Consumer Price Index: Concepts, Sources and Methods. Australian Bureau of Statistics.

ABS (2006). Catalogue number 6401.0. Consumer Price Index, Australia. Australian Bureau of Statistics.

Anari, A. and Kolari, J. (2002). House prices and inflation. Real Estate Economics, 30(1):67-84.

Anselin, L. and Le Gallo, J. (2006). Interpolation of air quality measures in hedonic house price models: Spatial aspects. Spatial Economic Analysis, 1(1):31-52.

Bogart, W. T. and Cromwell, B. A. (2000). How much is a neighbourhood school worth? Journal of Urban Economics, 47:280-305.

Bowes, D. R. and Ihlanfeldt, K. R. (2001). Identifying the impacts of rail transit stations on residential property values. Journal of Urban Economics, 50:1-25.

Carroll, T. M., Clauretie, T. M., and Jensen, J. (1996). Living next to godliness: Residential property values and churches. Journal of Real Estate Finance and Economics, 12:319-330.

Chun, G. H., Sa-Aadu, J., and Shilling, J. D. (2002). REIT returns and inflation: Perverse or reverse causality effects. Journal of Real Estate Finance and Economics, 24(3):301317.

Chun, G. H., Sa-Aadu, J., and Shilling, J. D. (2004). The role of real estate in an institutional investor's portfolio revisited. Journal of Real Estate Finance and Economics, 29(3):295-320.

Follain, J. R. and Ling, D. C. (1988). Another look at tenure choice, inflation, and taxes. AREUEA Journal, 16(3):207-229.

Gibbons, S. and Machin, S. (2005). Valuing rail access using transport innovations. Journal of Urban Economics, 57:148-169.

Goetzmann, W. N. and Ibbotson, R. G. (1990). The performance of real estate as an asset class. Journal of Applied Corporate Finance, 3:64-76.

Gyourko, J. and Linneman, P. (1988). Owner-occupied homes, income-producing properties, and REITs as inflation hedges: empirical findings. Journal of Real Estate Finance and Economics, 1:347-372. 
Gyourko, J. and Nelling, E. (1996). Systematic risk and diversification in the equity REIT market. Real Estate Economics, 24.

Harris, J. C. (1989). The effect of real rates of interest on housing prcies. Journal of Real Estate Finance and Economics, 2:47-60.

Hughes, W. T. (1995). Risk analysis and asset valuation: A Monte Carlo simulation using stochastic rents. Journal of Real Estate Finance and Economics, 11:177-187.

Hwang, M., Quigley, J. M., and Young Son, J. (2006). The dividend pricing model: New evidence from the Korean housing market. Journal of Real Estate Finance and Economics, 32:205-228.

IMF (2004). IMF World Economic Outlook - September 2004. Technical report, International Monetary Fund.

Liu, C. H. (1994). An analysis of real-estate risk using the present value model. Journal of Real Estate Finance and Economics, 8:5-20.

Meese, R. and Wallace, N. (1994). Testing the present value relation for housing prices: Should I leave my house in San Francisco? Journal of Urban Economics, 35:245-266.

OECD (2005). OECD Economic Outlook 78, Volume 2005, Issue 2. OECD Publishing.

Painter, G. and Redfearn, C. L. (2002). The role of interest rates in influencing long-run home- ownership rates. Journal of Real Estate Finance and Economics, 25(2/3):243-267.

Poterba, J. (1984). Tax subsidies to owner-occupied housing: an asset market approach. Quarterly Journal of Economics, 99:729-745.

Reback, R. (2005). House prices and the provision of local public services: capitalization under school choice programs. Journal of Urban Economics, 57:275-301.

REIA (2006). Median rents for 3 bedroom houses in Australian capital cities. Real Estate Institute of Australia.

Reichert, A. K. (1990). The impact of interest rates, income, and employment upon regional housing prices. Journal of Real Estate Finance and Economics, 3:373-391.

Scott, L. O. (1990). Do prices reflect fundamentals in real estate markets? Journal of Real Estate Finance and Economics, 3:5-23.

Spellman, L. J. (1981). Inflation and housing prices. Journal of American Real Estate and Urban Economics Association, 9:205-222. 
Summers, L. H. (1981). Inflation, the stock market, and owner-occupied housing. American Economic Review, 71(2):429-434. 